\title{
A busca pela universalização do abastecimento de água e esgotamento sanitário: evolução, desafios e perspectiva. Um estudo de caso em Manaus-AM
}

\section{The search for the universalization of water supply and sewage system: evolution, challenges and perspective. A case study in Manaus-AM}

Jefferson da Silva Aragão - Mestre em Ciências Ambientais e Sustentabilidade na Amazônia (PPG/CASA)/Universidade Federal do Amazonas (UFAM), Manaus-AM. E-mail: jeff_ aragao@hotmail.com

João Tito Borges - Doutor em Engenharia Cível, UNICAMP, docente e pesquisador do Programa de Pós-Graduação em Ciências do Ambiente e Sustentabilidade na Amazônia (PPG-CASA)/Universidade Federal do Amazonas (UFAM), Manaus-AM. E-mail: thtborges@gmail.com

\begin{abstract}
Resumo
O objetivo do trabalho foi analisar o desafio da cidade de Manaus-AM em universalizar o acesso aos sistemas de abastecimento de água e esgotamento sanitário. $\mathrm{O}$ estudo tem característica descritiva com abordagem qualitativa e foi desenvolvido por meio da análise da série histórica do Sistema Nacional de Informações sobre o Saneamento (SNIS), que abarcou informações e indicadores operacionais de 2002 a 2015, como extensão da rede de água, extensão da rede de esgotos; índice de atendimento urbano de água; índice de atendimento urbano de esgoto. Concluiu-se que há significativa diferença entre o abastecimento de água e o esgotamento sanitário, sendo que o último atende a pouco mais de $10 \%$ da população da cidade. Considerou-se que o maior desafio da cidade é a ampliação do acesso ao sistema de esgotamento sanitário, principalmente no que tange às obras de infraestrutura urbana e à garantia da adesão da população aos sistemas.
\end{abstract}

\section{Palavras-chave}

Saneamento. Universalização. Urbanização. Meio Ambiente.

\begin{abstract}
The objective of this work was to discuss the challenge of universalizing access to water supply and sewage system in the city of Manaus - AM. The study has a descriptive characteristic with a qualitative approach and was developed through analysis of the historical series on the National Sanitation Information System (SNIS), which included information and operational indicators from 2002 to 2015, such as extension of the waters network, sewages networks; index of urban water services; index of urban sewages service. The research showed a significant difference between waters supply and sewages systems, the latter serving just over $10 \%$ of the population in the city. It was considered that the greatest challenge to the city is the expansion of access to the sanitaries sewages system, especially in what concerns to urban infrastructures work and to guarantee the population's adherence to the systems.
\end{abstract}

\section{Keywords}

Sanitation. Universalization. Urbanization. Environment. 


\section{INTRODUÇÃO}

Alcançar a universalização do saneamento é um dos anseios mais urgentes da população mundial, já que influencia diretamente na saúde pública, na qualidade de vida e no bem-estar social. A questão do acesso universalizado ao saneamento ganhou ainda maior importância no Brasil em 1999 com o advento da 1ํㅡㄹ Conferência Nacional de Saneamento, mas foi em 2007 com a Lei Federal $\mathrm{n}^{\mathrm{o}}$ 11.445/2007 que o setor passou a ter um marco regulatório, estabelecendo normas gerais de gestão dos serviços de saneamento (BRASIL, 2007).

Segundo a Lei Federal, o objetivo primordial das ações nos quatro componentes do saneamento brasileiro é alcançar a universalização ${ }^{1}$ dos serviços. Previsto no artigo 52 da mesma lei, o Plano Nacional de Saneamento Básico (PLANSAB), consolidado em 2014, prevê dentre outros a universalização dos serviços de abastecimento com água potável até 2023 e de esgotamento sanitário até 2033. Contudo, a dinâmica urbana vivenciada pela população brasileira mostra uma realidade dura, sobretudo nos estados da região Norte que, mesmo tendo avançando no que se refere às políticas públicas, não garantiu que o setor nessa região evoluísse. Esses estados ainda possuem os piores índices de acesso ao abastecimento de água potável e ao quase inexistente serviço de esgotamento sanitário como mostram o Sistema Nacional de Informações sobre o Saneamento (SNIS, 2015) e o ranking do Saneamento promovido pelo Instituto Trata Brasil (2016).

Dada a deficiência exposta de forma mais grave na região Norte, optou-se pela realização de um estudo de caso, pois, "investiga um fenômeno contemporâneo (o caso), em profundidade e em seu contexto no mundo real, especialmente quando as fronteiras entre os fenômenos e o contexto possam não estar claramente evidentes" (YIN, 2015, p. 17), realizado em Manaus-AM, uma vez que, dentre as cidades amazonenses, é a que detém a maior concentração populacional e a única que possui gestão desses serviços a cargo de uma empresa privada, além de ser aquela com a melhor estrutura urbana em se tratando dos SAE² (ARAGÃO; BORGES, 2016). Foi utilizada uma abordagem descritivaexploratória que torna o objeto da pesquisa mais familiar ao pesquisador uma vez que o conteúdo a ser estudado é pouco explorado, permitindo desta forma

\footnotetext{
1 O termo remete aos direitos iguais e a dignidade da pessoa humana que surgiu após a segunda guerra mundial, no preâmbulo da Declaração Universal dos Direitos Humanos, embora a universalização seja definida de forma genérica para esta pesquisa optou-se pela ideia definida no marco regulatório do setor de saneamento (Lei Federal $n^{\circ}$ 11.445/2007) que em linhas gerais diz respeito ao acesso equitativo de toda a população ao mesmo serviço (SAE).

2 Para separação e melhor compreensão, o saneamento não foi tratado de acordo com o conceito mais amplo, e sim a partir da delimitação de ações, ou seja, sob a ótica dos SAE - Sistema de Abastecimento de água e Esgotamento sanitário sendo esses importantes componentes do saneamento.
} 
conhecer as características, causas e consequências de um fenômeno (GIL, 2008; RICHARDSON, 2015; SEVERINO, 2007). Desse modo, o método qualitativo torna-se o mais indicado. "O método qualitativo é o que se aplica ao estudo da história, das relações, das representações, das crenças, das percepções e das opiniões, produto das interpretações que os humanos fazem a respeito de como vivem, constroem seus artefatos e a si mesmos" (MINAYO, 2006, p. 57). Para tal análise, utilizou-se o banco de dados do Sistema Nacional de Informações sobre o Saneamento (SNIS) - Série histórica, que abarcou informações e indicadores operacionais de 2002 a 2015, descritos no Quadro 1 e divididos em dois grupos (abastecimento de água e esgotamento sanitário). A temporalidade empregada nessa pesquisa foi definida por evidenciar quaisquer traços de evolução ou não dos sistemas no período analisado.

Quadro 1 - Grupos de análise dos componentes do SAE do SNIS série histórica de 2002 a 2015 da cidade de Manaus-AM

\begin{tabular}{|c|c|c|c|}
\hline \multicolumn{2}{|c|}{ Grupo 01: Abastecimento de Água } & \multicolumn{2}{|c|}{ Grupo 02: Esgotamento Sanitário } \\
\hline \multicolumn{4}{|c|}{ Informações } \\
\hline \multicolumn{2}{|c|}{$\begin{array}{l}\text { AG005 - Extensão da rede de água: } \\
\text { Comprimento total da malha de distribuição } \\
\text { de água, incluindo adutoras, subadutoras } \\
\text { e redes distribuidoras e excluindo ramais } \\
\text { prediais, operada pelo prestador de } \\
\text { serviços, no último dia do ano de referência. } \\
\text { Unidade: km. }\end{array}$} & \multicolumn{2}{|c|}{$\begin{array}{l}\text { ES004 - Extensão da rede de esgotos: } \\
\text { Comprimento total da malha de coleta de } \\
\text { esgoto, incluindo redes de coleta, coletores } \\
\text { tronco e interceptores e excluindo ramais } \\
\text { prediais e emissários de recalque, operada } \\
\text { pelo prestador de serviços, no último dia } \\
\text { do ano de referência. Unidade: } \mathrm{km} \text {. }\end{array}$} \\
\hline \multicolumn{4}{|c|}{ Indicadores } \\
\hline \multicolumn{2}{|c|}{$\begin{array}{l}\text { IN023 - Índice de atendimento urbano } \\
\text { de água }\end{array}$} & \multicolumn{2}{|c|}{$\begin{array}{c}\text { IN047 - Índice de atendimento urbano } \\
\text { de esgoto referido aos municípios } \\
\text { atendidos com esgoto }\end{array}$} \\
\hline $\begin{array}{c}\text { Forma de Cálculo } \\
\text { do indicador do } \\
\text { SNIS }\end{array}$ & $\begin{array}{l}\text { Informações } \\
\text { envolvidas }\end{array}$ & \begin{tabular}{|c|} 
Forma de Cálculo \\
do indicador do \\
SNIS
\end{tabular} & $\begin{array}{l}\text { Informações } \\
\text { envolvidas }\end{array}$ \\
\hline$\frac{\mathrm{AG} 026}{\mathrm{GE} 06 \mathrm{a}} \times 100$ & $\begin{array}{l}\text { AG026: População } \\
\text { urbana atendida com } \\
\text { abastecimento de água } \\
\text { G06A: População } \\
\text { urbana residente } \\
\text { dos municípios com } \\
\text { abastecimento de água } \\
\text { POP_URB: População } \\
\text { urbana do município } \\
\text { do ano de referência } \\
\text { (Fonte: IBGE). } \\
\text { Unidade: Percentual }\end{array}$ & $\frac{\mathrm{ES} 026}{\mathrm{GE} 06 \mathrm{~b}} \times 100$ & $\begin{array}{l}\text { ES026: População } \\
\text { urbana atendida com } \\
\text { esgotamento sanitário } \\
\text { G06B: População } \\
\text { urbanaresidente } \\
\text { dos municípios com } \\
\text { esgotamento sanitário } \\
\text { POP_URB: População } \\
\text { urbana do município } \\
\text { do ano de referência } \\
\text { (Fonte: } \\
\text { Unidade: } \text { Percentual }\end{array}$ \\
\hline
\end{tabular}

Fonte: Informações retiradas integralmente do SNIS, 2015. 
A escolha dessas informações/indicadores se deu por propiciar uma visão sistêmica da evolução dos serviços (abastecimento de água e esgotamento sanitário) e como a estrutura operacional empregada na cidade afeta o atendimento da população local e consequentemente o acesso a estes serviços. Assim, esse artigo se propõe a analisar o desafio da cidade de Manaus-AM em universalizar o acesso aos sistemas de abastecimento de água e esgotamento sanitário. O presente estudo pode dar suporte aos atores envolvidos na gestão do saneamento em Manaus, pois traz informações úteis aos gestores públicos e privados e principalmente esclarecer a sociedade sobre as dificuldades encontradas para a universalização destes dois serviços.

\section{O ACESSO À ÁGUA POTÁVEL DE QUALIDADE $\mathrm{E}$ AO SANEAMENTO ADEQUADO: UM DIREITO DE TODOS}

A história humana há muito destaca a importância de toda a população ter acesso à água potável e ao saneamento adequado, mas só recentemente a resolução A/RES/64/292 de julho de 2010 da Assembleia Geral da ONU reconheceu "o direito à água potável e limpa e ao saneamento como um direito humano e essencial para o pleno gozo da vida e todos os direitos humanos" (UN, 2010, p. 2).

No Brasil, mesmo que de forma indireta, a ideia de que a população tem direito ao acesso à água potável de qualidade por meio do abastecimento de água e dos serviços de coleta e tratamento de esgoto já era prevista na Constituição Federal, por meio dos direitos fundamentais e da dignidade da pessoa humana que visa, sobretudo, garantir à população seus direitos mais básicos e indissociáveis capazes de permitir a vida. E sua importância é tal que a CF/88 fixou os direitos fundamentais antes, do conjunto de leis que regem e fundamentam a organização do Estado brasileiro. Assim:

[os] diretos fundamentais são os considerados indispensáveis ao ser humano, e são necessários para assegurar a todos uma existência digna, livre e igual. Não basta o Estado reconhecê-los formalmente, deve buscar concretizá-los, incorporá-los do dia a dia dos cidadãos e de seus regentes (PINHO, 2003, p. 66).

Dessa maneira, permitir que a população tenha acesso a esses direitos é na verdade garantir a dignidade da pessoa humana:

É a qualidade intrínseca e distintiva de cada ser humano que faz merecedor do mesmo respeito e consideração por parte do Estado e da comunidade, implicando, neste sentido, um complexo de direitos e deveres fundamentais que assegurem a pessoa tanto contra todo e qualquer ato de 
cunho degradante e desumano, como venham a lhe garantir as condições essenciais mínimas para uma vida saudável, além de propiciar e promover sua participação ativa e corresponsável nos destinos da própria existência e da vida em comunhão com os demais seres humanos (SARLET, 2002, p. 62 apud MARMELSTEIN, 2014, p. 16).

Ainda sobre a dignidade da pessoa humana é impreterível entender que “a noção básica de respeito ao outro sintetiza com perfeição o princípio da dignidade da pessoa humana, assim a dignidade é um atributo e não um privilégio de poucos, mas de toda humanidade" (MARMELSTEIN, 2014, p. 62-63). Acerca de proposição é importante também lembrar que a "dignidade da pessoa humana é um dos principais valores da ordem social e jurídica brasileira e que deve ser entendido como absoluto respeito aos seus direitos fundamentais, assegurando condições dignas de existência para todos" (PINHO, 2003, p. 62).

Todavia, não basta apenas garantir que toda a população tenha acesso a esses direitos sem entender que vivemos em "uma sociedade de massa caracterizada por um crescimento desordenado e brutal avanço tecnológico" (FIORILLO, 2013, p. 47), que, por vezes, se torna excessivamente predatória unindo-se a uma economia de alto consumo, tão desnecessária que a humanidade está disposta a exaurir suas reservas naturais pela maximização de seu consumo.

\section{ENTENDENDO A UNIVERSALIZAÇÃO}

Mesmo estando indiretamente previsto em lei por meio da Constituição federal, apenas com a aprovação da Lei Federal nº 11.445/2007 que não só o termo universalização foi definido, mas também todo o arcabouço técnico necessário para tal. E dada a complexidade da discussão, e das externalidades do setor, optou-se para essa pesquisa utilizar o conceito definido pela Lei $\mathrm{n}^{\mathrm{o}}$ 11.445/2007 que diz no inciso III do art. $2^{\circ}$ que "universalização é ampliação progressiva do acesso ao saneamento básico ${ }^{3}$ para os domicílios ocupados do país" (BRASIL, 2007, p. 2).

Dada a amplitude dos termos e dada o delineamento do tema, é importante entender que apenas dois dos componentes do saneamento são utilizados para

\footnotetext{
Embora a literatura especializada seja rica em definições, optou-se por utilizarmos a definição emprega pela mesma lei, por ser considerada mais completa e atualizada possível. Ao qual define o saneamento básico como sendo um conjunto de serviços, infraestruturas e instalações operacionais, mas para esta pesquisa utilizamos apenas dois componentes, são eles: a) abastecimento de água potável: constituído pelas atividades, infraestruturas e instalações necessárias ao abastecimento público de água potável, desde a captação até as ligações prediais e respectivos instrumentos de medição; b) esgotamento sanitário: constituído pelas atividades, infraestruturas e instalações operacionais de coleta, transporte, tratamento e disposição final adequados dos esgotos sanitários, desde as ligações prediais até o seu lançamento final no meio ambiente (BRASIL, 2007).
} 
inferências, são eles: o abastecimento de água e o esgotamento sanitário, devendo então entender que a universalização, ao menos para essa pesquisa, é do ponto de vista do abastecimento de água e esgotamento sanitário. Ou seja, universalizar enquanto direito é ampliar o acesso da população aos serviços de abastecimento de água e esgotamento sanitário.

Nesse ínterim:

O significado desses direitos tem sido progressivamente interpretado e compreendido. $\mathrm{O}$ direito humano à água tem sido considerado como compreendendo a água física e financeiramente acessível, segura, aceitável e continuamente disponível para o uso pessoal e doméstico. Quanto ao direito humano ao esgotamento sanitário, entende-se que este serviço deva ser física e financeiramente acessível, prover segurança ao usuário, ser culturalmente aceitável e disponível para todos os usuários e em todas as esferas da vida, além de assegurar dignidade e privacidade. Enxergar o acesso à água e ao esgotamento sanitário sob a lente dos direitos humanos supõe também observar seus princípios fundantes, como o direito à participação, o direito ao acesso à informação, a igualdade e não discriminação, a responsabilidade por parte de governos e prestadores de serviço e a sustentabilidade (HELLER, 2016, p. 1).

Ou seja, as mudanças orientadas pelos direitos humanos implicam, dentre outras, em mudança na postura do governo, pois a prática é quase sempre discriminatória. Um exemplo seria a acessibilidade financeira não só das prestadoras, mas também dos titulares do serviço em resguardar o acesso das pessoas economicamente vulneráveis. Dessa forma, “o corte da ligação de uma moradia ao sistema público, por ausência de pagamento é violação a esse direito", como nos lembra Heller (2016, p. 2). Todavia, Bertollo (2016) nos situa que embora esses serviços (SAA e SES) estejam na categoria de direitos essenciais há uma controvérsia. A Lei Federal nº 11.445/2007 no art. 40 §3ํㅗㄹere a possibilidade de interrupção dos serviços em caso de inadimplência, sendo esse um grave retrocesso político, econômico e social vivido pela população brasileira.

Sobre a importância da água, faz-se necessário entender:

O direito a água não é um vale-tudo permitindo que um use a quantidade que bem entender para qualquer finalidade; em vez disso, ele garante água potável limpa e acessível, assim como saneamento, para uso pessoal e doméstico para todos. [...] fundamentalmente o direito humano à água é uma questão de justiça, não de caridade. Ele exige um desafio às estruturas de poder atuais que dão suporte ao acesso às reservas de água doce do mundo, cada dia mais escassas (BARLOW, 2015, p. 17).

É evidente que os recursos hídricos devem ser levados em consideração, já que sem água, não existiria esgoto, ou seja, não existiria o SAE, e a preocupação 
com água, é de longe o mais urgente dos problemas ambientais vividos no mundo, prover água de qualidade a todos é questão de sobrevivência e se caracteriza como princípio à vida. É possível ainda corroborar, "O acesso dos serviços de saneamento básico é condição necessária à dignidade da pessoa humana e, particularmente, à sua sobrevivência" (GALVÃO, 2009, p. 549). "Dadas as externalidades dos serviços e a sua essencialidade se tornam a questão da universalização e equidade ${ }^{4}$ fundamentais aos cidadãos" (MADEIRA, 2010, p. 126).

Presume-se que:

As políticas concernentes ao saneamento devam se fundamentar no princípio que esses serviços constituem um direito social do cidadão, em outras palavras, é obrigação do Estado garantir o acesso universal a eles. Essa conceituação apoia-se nos princípios da universalidade e da equidade, de acordo com os quais todo cidadão independente de sua classe social, gênero, origem étnica, ou qualquer outro fator de diferenciação social, tem direito irrestrito aos bens e serviços julgados essenciais à manutenção da vida numa sociedade civilizada (HELLER, 2013, p. 30).

"A combinação do acesso à água potável e ao sistema de esgotamento sanitário é condição para se obter resultados satisfatórios também na luta para a erradicação da pobreza e da fome, para a redução da mortalidade infantil e pela sustentabilidade ambiental" (CAMPANHA DA FRATERNIDADE, 2016). Entendido, então, que o acesso à água potável e ao saneamento adequado é um direito e que universalizar é a ampliação progressiva desses direitos a todos os cidadãos, faz-se necessário entender as nuances dessa relação.

Foi apenas no ano 2000, por meio da Declaração do Milênio das Nações Unidas, que se constituiu um esforço internacional para alcançar o desenvolvimento em diversos setores e temas de relevância, entre ele o saneamento básico e o acesso à água potável, proposto pelo ex-secretário geral das Nações Unidas, Kofi A. Annan. Um dos pontos de grande discussão em relação à primeira agenda dos Objetivos do Milênio (2000-2015) se deu pelo fato de considerar apenas os países ao sul (em desenvolvimento) como responsáveis por atingir as metas. Em suma, a crítica era porque apenas os países em desenvolvimento deviam criar ações para alcance das metas, tal atitude poderia de certa forma mascarar problemas para fortalecimento das ações nos países desenvolvidos.

Mesmo com os avanços tecnológicos e os altos investimentos, o mundo não alcançou a meta dos Objetivos do Milênio (ODM) para o saneamento, que visava reduzir pela metade a proporção da população sem saneamento básico e assim estender o acesso de 54\% para 77\% da população global até 2015. Mesmo

\footnotetext{
Equidade: De Souza (2007 p. 766) destaca que o entendimento que a equidade "mais do que tratar todos iguais, teria um valor de justiça, ou seja, de se buscar dar mais a quem precisa mais".
} 
não sendo cumprida a meta ${ }^{5}$ dos ODM houve um progresso, contudo ainda existem 2,4 bilhões de pessoas sem qualquer melhora nos serviços de saneamento e entre eles quase 950 milhões de pessoas que ainda praticam a defecação a céu aberto (WHO/UNICEF JMP, 2015).

Ao final de 2015 uma nova agenda foi divulgada e passou a se chamar Objetivos do Desenvolvimento Sustentável (ODS). Nessa nova versão da agenda, as nações do mundo se comprometeram em trabalhar para alcançar tais metas até 2030, pois se entendeu que para a efetividade das ações, tanto países em desenvolvimento como desenvolvidos, deviam criar ações para alcance dos ODS. Em relação ao saneamento e seus desdobramentos, destaca-se o $6^{\circ}$ objetivo que, dentre outros, assegura a disponibilidade e a gestão sustentável da água e saneamento visando alcançar o acesso universal e equitativo ao saneamento (UN, 2015).

É necessário ressaltar a importância da busca pela equidade, universalidade e os ODS como políticas governamentais. Em um comunicado de 2010, a ONU ${ }^{6}$ destacou o direito à água e ao saneamento como centrais na elaboração de políticas e implementação de ações das do então ODM. Por outro lado, mesmo sendo a base das ditas políticas da ONU, é necessário levar em consideração as divergências de planejamento de ações operacionais ao acesso à água potável e ao saneamento como um todo, pois até a agenda 2015 eram realizadas ações, que podem ser consideradas apenas paliativas. Nesse contexto expõe-se:

Uma das principais medidas de acesso à água potável usadas pela ONU é o número de tubulações instaladas em um país. No entanto, só porque há um cano não significa que haja água limpa saindo dele, e mesmo se houvesse, pode estar distante de onde as pessoas realmente vivem. Além disso, se as tarifas sobre a água forem altas demais e não puderem ser pagas, essas tubulações novas serão irrelevantes. Eu testemunhei pessoas darem as costas para tubulações novas trazendo água limpa de rios porque o acesso exigia dinheiro para hidrômetros pré-pagos; elas iam então aos rios mesmo sabendo da existência de cólera ao longo de suas margens (BARLOW, 2015, p. 30).

A cobrança de tarifas é um dos fatores que dificultam a universalização, sobretudo em países com altos índices de pobreza absoluta da população. Nesses casos, é impreterível a intervenção do governo, garantindo o acesso à água potável

5 A meta dos ODM era alcançar 77\% da população mundial com acesso adequado ao saneamento. Ficamos 9 pontos percentuais abaixo, ou seja, $68 \%$ da população mundial agora possui alguma melhora nos serviços de saneamento.

6 O comunicado intitulado General Assembly, Human Rights Council Texts Declaring Water, Sanitation Human Right 'Breakthrough'. Ficou publicado pelo departamento de informações públicas da ONU em 25 de outubro de 2010. 
e a condições mínimas de higiene para a sua população. Contudo, os esforços para alcançar a universalização destes serviços esbarram em um aspecto político e de autopromoção. A Assembleia Geral do Conselho de Direitos Humanos da ONU, realizada em 2010, publicou um texto em que Catarina de Albuquerque ${ }^{7}$ afirma que os efeitos perversos que os ODM causaram dizem respeito aos pobres, migrantes, refugiados, moradores de favelas e minorias étnicas que ainda não têm acesso á àgua ou ao esgotamento sanitário e são esquecidos por seus governantes, estes orgulhosos apenas pelas conquistas das "metas" dos ODM (UN, 2010).

Porém, alcançar as metas não é para promoção de um país, sendo inaceitável que existam pensamentos como esses. As metas existem para um bem geral de uma nação, ou para o mundo no caso do acesso à água, ao saneamento adequado, à pobreza e à paz. Tal declaração apenas reforça o relato de Barlow, citado anteriormente, em que um cano não é condição suficiente para dizer que a população tem água, quanto mais de qualidade. A dificuldade de acesso aos SAE (Sistemas de Abastecimento de Água e Esgotamento Sanitário), como sendo serviços indispensáveis à condição humana por parte da população, são apenas uns dos problemas enfrentados pela humanidade. Além do mais, há pobreza e miséria, associados a um padrão de crescimento econômico que não é capaz de remediar essas disparidades (THE WORLD RESOURCE INSTITUTE, 1992). "A carência de instalações suficientes de abastecimento de água para as populações constitui uma das maiores dívidas sociais ainda persistentes no mundo. Permanece um contingente considerável da população mundial ainda carente de acesso a esse bem" (FUNASA, 2015, p. 65), apesar de o mesmo ser um direito indiscutível do ser humano.

Proporcionar instalações de saneamento às populações urbanas é um desafio. O saneamento inadequado ocasiona problemas tão graves quanto à própria ausência de saneamento, podendo ser citadas as doenças as principais consequências ao homem, o dano ambiental que a falta de rede ou rede sucateada pode provocar (WRIGHT, 1997). Em suma, universalizar o abastecimento de água e esgotamento sanitário (SAE) é promover a justiça social e igualitária permitindo que todos tenham acesso ao mesmo nível de serviços a um preço justo e para isso é necessário promover estratégias que minimizem as desigualdades e promovam ações que auxiliem a população carente a sair da linha da pobreza extrema.

\footnotetext{
Relatora especial do Conselho de Diretos Humanos sobre o direito humano à água potável segura e ao saneamento, discutiu no comunicado de imprensa intitulado General Assembly, Human Rights Council Texts Declaring Water, Sanitation Human Right 'Breakthrough' da ONU em 25 de outubro de 2010, dentre outros sobre os "avanços e os desafios em transformar o direito à água e ao saneamento em uma realidade para os bilhões de pessoas em todo o mundo que ainda não tinham acesso à água potável e ao saneamento adequado”.
} 


\section{O ACESSO AOS SAE NO BRASIL: CAMINHANDO PARA UNIVERSALIZAÇÃO?}

No Brasil o saneamento é historicamente deficiente. A situação no setor entrou em declínio com a extinção do Banco Nacional de Habitação (BNH), em 1986, pois encerraram os investimentos do Plano Nacional de Saneamento (PLANASA). Lopes (2016), Britto (2006) e Madeira (2010) concordam que a extinção do plano deixou o setor, que já estava em declínio, com índices bastante insatisfatórios, o que, por sua vez, ajudou a estagnar o acesso aos SAE no país. Desde então, o setor como um todo permaneceu em um hiato, não havia regulação e nem a titularidade dos serviços era clara, contudo, com o advento da Lei Federal n⿳⺈ 11.445/2007, o setor tomou novo fôlego e desde então há avanços, lentos, mais, ainda assim avanços. A referida lei, além de se tornar o marco regulatório que o setor carecia, é ainda suporte para a Política Nacional do Saneamento Básico (PLANSAB). E nessa tentativa de ampliar os esforços, o marco legal, dentre outras atribuições, institui a obrigação do cumprimento das condições e metas estabelecidas nos contratos por parte das prestadoras e a obrigatoriedade da elaboração dos planos municipais de acordo com os quatro componentes primordiais do saneamento segundo a Lei Federal n⿳o 11.445/2007 (abastecimento de água, coleta e tratamento de esgotos drenagem e manejo de águas pluviais, limpeza urbana e manejo de resíduos sólidos).

A oferta de água e esgoto tratados é um gargalo histórico para o desenvolvimento do país. O Sistema Nacional de Informações sobre Saneamento (SNIS) indicou que o abastecimento de água tratada no Brasil atingia 82,5\% da população em 2013 e apenas 48,6\% tinham acesso à coleta de esgoto (PORTAL BRASIL, 2016). Os dados revelam a grande disparidade entre o acesso aos SAA e SES no Brasil, mais que um problema histórico é de cunho social e econômico. “Os problemas de falta d'água que ocorrem atualmente no mundo, especialmente no Brasil, resultam da baixa eficiência em fornecimento e também pelos grandes volumes de perdas, sobretudo em adução" (GIATTI, 2007, p. 141). As perdas de fato são um problema e mostram a realidade vivida pela população brasileira que precisa muitas vezes recorrer a métodos ilegais para ter acesso ao menos à água para consumo, e dependendo da forma como é feita essa retirada, a água pode ser de baixa qualidade trazendo transtornos à população.

O compromisso de ofertar água potável e esgoto tratado foi reforçado pelo Brasil no ano de 2016, quando o país assumiu o saneamento como um dos Objetivos de Desenvolvimento Sustentável (ODS) para serem cumpridos até 2030. Na tentativa de reverter este quadro precário em que vive o país que 
a União elaborou o PLANSAB. O plano completa quatro anos em 2018, tendo como principal objetivo universalizar o acesso à água potável até 2023 e atingir um índice considerado adequado de 93\% de coleta de esgoto até 2033. Lopes (2016) salienta que o PLANSAB definiu um investimento no valor de R\$ 15 bilhões a cada ano para universalizar o saneamento, porém, até agora nada foi cumprido. Os investimentos no setor estão abaixo do esperado, a crise econômica e política que o país passa piorou os investimentos que agora estão em segundo plano. $\mathrm{O}$ mesmo autor ainda menciona que a participação massiva da iniciativa privada é fator fundamental para alcançar a universalização no país não em 2033, como previsto no PLANSAB, mas em 2054.

De toda forma, o PLANSAB teve seu mérito em traçar metas ousadas para o país, onde finalmente sabe-se que o poder concedente dos serviços é o município e a ele cabe o planejamento das ações que visam alcançar a universalização. Por outro lado, o dia a dia é diferente do mundo idealizado.

O excesso de burocracia, decorrente das demasiadas normas e procedimentos de órgãos governamentais, enseja a morosidade dos processos, sobretudo na esfera ambiental, combinada com a pouca eficiência na aplicação dos recursos públicos e com problemas de gestão [...] nesse contexto, questões aparentemente simples ou de menor relevância podem demandar anos para serem resolvidas, além de consumirem muito tempo e recurso das firmas. O excesso de burocracia eleva os custos das empresas, onera o preço de produtos e serviços, desestimula os negócios e os investimentos produtivos, entre outros efeitos deletérios, constituindo um claro obstáculo ao desenvolvimento do país. Todos esses fatores fazem com que a implementação de projetos essenciais ao aperfeiçoamento da infraestrutura brasileira configure uma tarefa difícil e repleta de ineficiências (CNI, 2016, p.1).

A ineficiência é talvez o maior dos entraves vividos pela sociedade brasileira em qualquer setor. Ao longo das décadas o setor de saneamento ficou sufocado pela falta de direcionamento e focado em se discutir de quem era a responsabilidade pela gestão.

\section{A BUSCA PELA UNIVERSALIZAÇÃO: O CASO DE MANAUS-AM}

O Brasil detém 13\% da água doce do mundo, cuja distribuição geográfica, no entanto, é desigual. A maior parte dessa água encontra-se na região Amazônica, embora possua uma extensão elevada, é nessa região que se encontra o menor contingente populacional do país ${ }^{8}$ (IBGE, 2010). Neste recorte geográfico está

O último Censo demográfico realizado no Brasil em 2010 pelo Instituto Brasileiro de Geografia 
a área urbana do município de Manaus, capital do estado do Amazonas, em área de unidade territorial total de $11.401,092 \mathrm{~km}^{2}$, e uma população estimada de 2.094.391 habitantes, segundo o IBGE (2016).

Entre os anos 1970 e 1999, os serviços de abastecimento de água, coleta e tratamento de esgoto ficaram a cargo da empresa Companhia de Saneamento do Estado do Amazonas (COSAMA) e, a partir do ano 2000, a Prefeitura Municipal de Manaus (PMM), então titular dos serviços permitiu a concessão das atividades de abastecimento de água e esgoto sanitário da cidade, à iniciativa privada vencedora da licitação, hoje denominada Manaus Ambiental (ARSAM, 2015). Os serviços de água e esgoto oferecidos pela COSAMA eram precários e a empresa passava por sérios problemas, operacionais, financeiros e por alta inadimplência dos consumidores, o que agravou a sua crise (OLIVEIRA, 2011). Nesse período, sob justificativa que tanto estado e município não tinham como fazer elevados investimentos, o prefeito da época, Amazonino Mendes, abriu concorrência para a "privatização" dos serviços de água e esgoto da cidade, o que permitiu um ente privado gerir o sistema por meio da concessão (CASTRO, 2008). A concessão se deu em um período de grandes mudanças na gestão pública, quando a lei federal $\mathrm{n}^{\circ}$ 8.987/1995 garantiu que empresas privadas pudessem gerir por tempo determinado os serviços antes exclusivos do estado e do município, a fim de garantir a qualidade da oferta dos mesmos à população.

Nos primeiros anos da gestão privatizada em Manaus muito se questionou sobre sua eficiência operacional, decorrente em grande parte da insatisfação da população na época em relação aos serviços oferecidos. Ocorreram mobilizações sociais, o que culminou na criação de uma CPI, a fim de investigar as ações da empresa e o processo que garantiu a concessão, como noticiado na impressa local na época (CASTRO, 2008). Até o momento foram feitos 5 aditivos no contrato de concessão, onde ocorreram diversas alterações nas metas iniciais e outros quesitos, além de obras de infraestrutura (ARSAM, 2015).

Em pouco mais de quinze anos de concessão, é inegável a mudança na infraestrutura da cidade que hoje conta com 4 sistemas de abastecimento em funcionamento, são eles: Ponta do Ismael (ETA I e II, Complexo PROAMA, e Sistema Poços), divididos em captação, adução, distribuição e reservação. Já no sistema de esgotamento sanitário, o sistema se divide em dois: integrado e isolado. O primeiro é o mais antigo em funcionamento, oriundo da primeira concessão (dos ingleses em 1906) e atende bairros do centro e adjacências, e

e Estatística (IBGE) contabilizou que a região Norte possuía 11.664.509 habitantes, a região nordeste 38.821.246, a região Sudeste 74.696.178, a região Sul: 23.260.896 e a região CentroOeste 12.482.963 residentes na área urbana. 
o isolado que atende a diversos conjuntos habitacionais espalhados por vários bairros da cidade. Na Figura 1 é apresentada a evolução das extensões das redes de abastecimento e esgotamento sanitário em Manaus.

Figura 1 - Extensão das redes de água e esgoto na cidade de Manaus, segundo o SNIS série histórica de 2002 a 2015

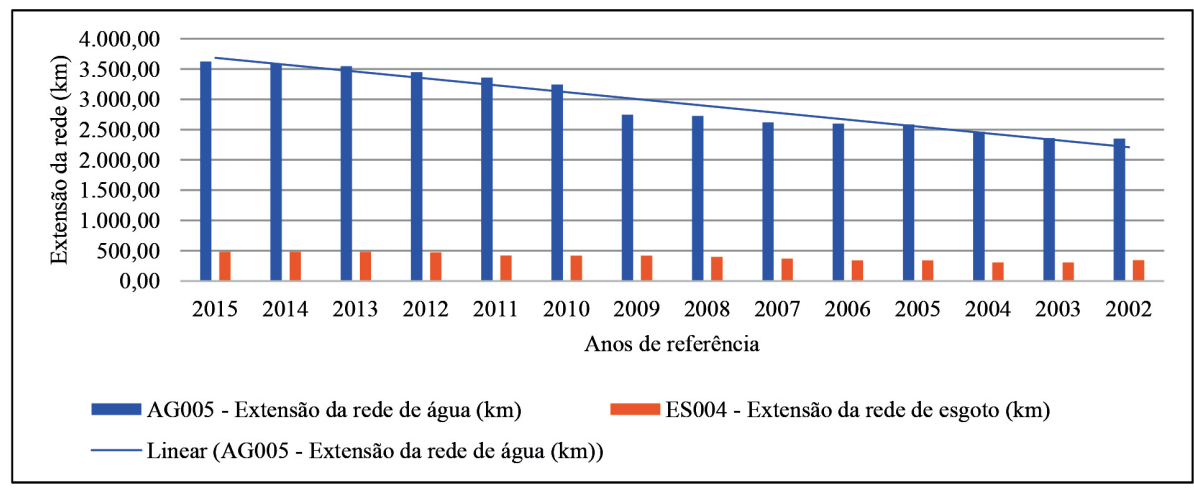

Fonte: Os autores com base nos dados agregados série histórica do SNIS (2002-2015).

É importante destacar que a extensão das redes reflete diretamente no atendimento dos serviços. A Figura 1 mostra um crescimento linear da extensão da rede urbana de abastecimento de água de Manaus. Em treze anos a rede cresceu pouco mais de 1.000,00 km, totalizando, em 2015, mais de 3.500,00 km. Mesmo com essa evolução no abastecimento de água da cidade, é difícil não comparar com a rede esgoto, que em números totais quase não mudou. A rede atual de esgoto abrange uma pequena parte da cidade, sendo que uma parcela significativa dessa rede já havia sido implantada na gestão dos ingleses no início do século XX. Mesmo com o advento da concessão desses serviços à Manaus Ambiental, não foi possível verificar uma evolução significativa na rede de esgoto.

Nesse aspecto, Giatti (2009, p. 28) afirma que "dimensão e cobertura da rede de captação de esgotos deve ser equivalente à rede de distribuição de água potável. Isso porque cada litro de água consumida irá gerar aproximadamente o mesmo volume em águas servidas". As dimensões das redes, como demonstrado, são desproporcionais, assim sendo, apenas uma pequena parcela da água distribuída é coletada e tratada na forma de esgoto sanitário, o que torna o problema mais sério. Em 2015 a extensão da rede de esgoto, como mostra a Figura 2, não chegou nem a $500 \mathrm{~km}$, se contrapondo ao sistema de abastecimento que tem uma extensão de mais de $3.500 \mathrm{~km}$. No Plano Municipal de Saneamento Básico de Manaus (MANAUS, 2014, p. 154) é relatado: 
Nos bairros onde não há sistemas de coleta, as fossas, são utilizadas com frequência ou o esgoto é despejado diretamente nos cursos d'água. Nas vias pavimentadas, os esgotos são ligados ao sistema de drenagem pluvial atingindo os pequenos cursos d'água que deságuam no rio Negro, afluente do rio Amazonas.

Os resultados apresentados na Figura 2 permitem concluir que o abastecimento foi priorizado em relação ao esgotamento sanitário, fato este confirmado pelo PMSB (MANAUS, 2014, p. 154) que na ausência de recursos para saneamento básico, sempre foram priorizados os projetos de abastecimento de água. Entretanto, tal prática é ineficiente e acarreta problemas como a discrepância nos tamanhos das redes e no atendimento da população. Oliveira (2011) relatou que as zonas norte e leste da cidade conviviam com os dois problemas, tanto de abastecimento de água quanto de ausência de rede coletora e de tratamento de esgoto de forma acentuada. Contudo, a situação foi amenizada com início do funcionamento do programa PROAMA, em 2013, que beneficiou a população dessas zonas, trazendo qualidade e certa regularidade do serviço de abastecimento de água. Contudo, o sistema de poços ainda está ativo e operando nessas áreas contribuindo para o atendimento da população (ARSAM, 2015).

O Brasil é um país de grandes e profundas diferenças, marcadas pela falta de compromisso dos governantes, pela falta de estrutura urbana e crescimento desordenado, um país onde a riqueza se concentra nas mãos de poucos, e que os pobres são obrigados a pagar pelo serviço que muitas vezes não recebem. Em relação aos SAE, existem grandes desafios a serem superados, sobretudo na Amazônia, onde a equidade é praticamente inexistente.

Figura 2 - Atendimento urbano dos SAE na cidade de Manaus-AM, segundo o SNIS série histórica de 2002 a 2015

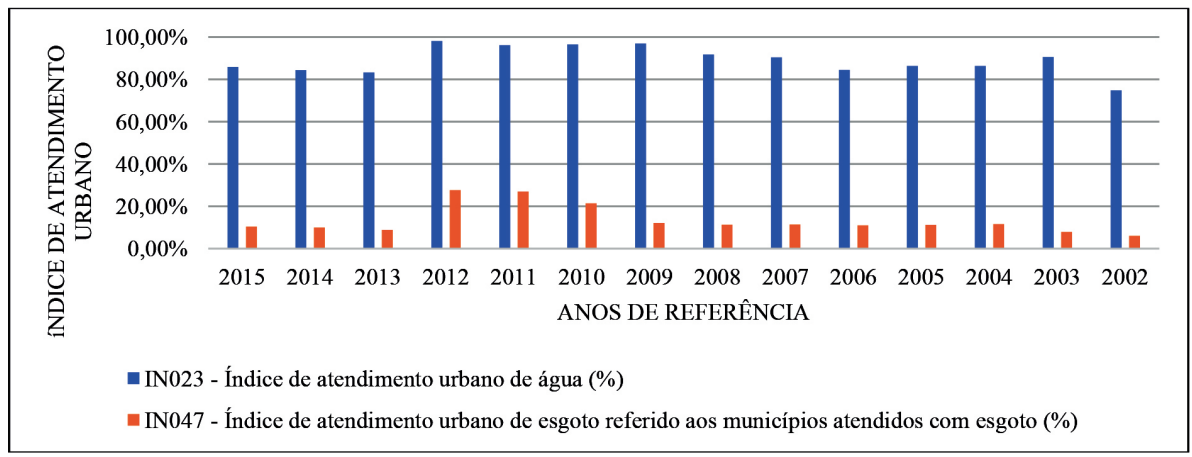

Fonte: Os autores com base nos dados agregados série histórica do SNIS (2002-2015) 
O problema do esgotamento sanitário fica ainda mais evidente quando se compara o atendimento à população dos dois sistemas. Entre os anos de 2002 e 2009 a taxa de atendimento se manteve praticamente inalterada, já a partir de 2010 até 2012 o crescimento chegou próximo de 30\%, pois nesse período houve um incremento com adição das redes do projeto PROSAMIM, conforme a Agência Reguladora dos Serviços do Amazonas (ARSAM, 2015). Os dados obtidos não explicam a queda ocorrida de 2013 a 2015. A extensão das redes e a cobertura populacional são os pontos que mais divergem. A situação do esgotamento sanitário é diferente do abastecimento, que "teoricamente" está mais próxima de ser resolvida e os dois conjuntos de dados estudados revelam o mesmo problema, a deficiência da rede de esgotamento sanitário na cidade.

Existem dois sistemas de esgotamento sanitário em operação em Manaus, um integrado e outro isolado, divididos em 5 bacias (Educandos, São Raimundo, Gigante, Tarumã e Colônia Antônio Aleixo, formando um sistema de 38 (trinta e oito) subsistemas, compostos por 62 (sessenta e duas) ETE ativas, três inativas e uma demolida. Mudar o sistema da forma como é hoje, integrado e isolado, para um sistema totalmente integrado teria um custo significativamente elevado e teria que contar com o auxílio do poder público. Da forma como é hoje atende a pouco mais de $10 \%$ da população. Acredita-se que para atender à população totalmente, esse número (62\%) teria que ser nove vezes maior, ou seja, 558 ETE isoladas para universalizar o sistema, até o fim da concessão por meados do ano 2045.

No caso de Manaus, em especial, os dados apresentados refletem negativamente no acesso da população aos serviços, como evidenciado no ranking do saneamento (2016) quando o município ficou em 97º lugar dentre as cem maiores cidades brasileiras pesquisadas, ou seja, a cidade cresce rapidamente e os serviços não acompanham esse crescimento. Quando houve a concessão, a justificativa dada pelo governo para tal empreitada era que uma empresa privada poderia gerir e alcançar resultados mais rápidos e com menos burocracia. Assim, 16 anos se passaram desde a concessão e este problema não foi resolvido. Durante todos esses anos diversas mudanças foram realizadas no contrato de concessão original por meio dos aditivos que permitiram a expansão do período de concessão.

É inegável que houve melhoras nos serviços de abastecimento entregues à cidade nesses anos, tanto em aspectos quantitativos quanto qualitativos, mas ainda está distante a universalização desses serviços. Pelos dados apresentados de esgotamento sanitário em Manaus, percebe-se que há necessidade de melhorias na gestão desse serviço e uma maior aproximação entre os entes envolvidos. Os investimentos realizados no esgotamento sanitário estão muito aquém do ideal e 
há quase um colapso no setor no país todo. Ocorreram poucos avanços, sendo necessário um esforço não somente das prestadoras de serviços, mas de todos os entes públicos e da população para universalizar os serviços de abastecimento de água e esgotamento sanitário no país.

Scaramussa e Henkes (2014) completam a afirmação acima dizendo que a prestação desses serviços enfrenta os mesmos desafios há décadas e que o modelo tradicional de gestão utilizado no setor não tem sido eficiente para alcançar a universalização, desafios esses que vão desde a implantação dos sistemas até a cobrança das tarifas. De mesma forma, um dos grandes problemas da implantação dos serviços é o fato de "não considerarem as particularidades locais e como consequência há inconsistências no modelo de gestão dos serviços, a forma como o Estado se organiza e a cultura político-institucional traz ineficiências e inefetividades" (HELLER, 2013, p. 180). Por sua vez, Madeira (2010) afirma que as tarifas cobradas devem ser suficientes para cobrir os custos da empresa e assegurar que a população inclusive de baixa renda, que não tem condições de pagar pelo serviço, tenha acesso a ele. Ou seja, a ampliação do sistema só é possível nos casos em que apenas a prestadora dos serviços investe sozinha nos sistemas por meio do pagamento das tarifas, contudo o planejamento errado ou a falta de planejamento, aumentam os custos para levar esses serviços à população.

\section{CONSIDERAÇÕES FINAIS}

A cidade de Manaus passa pelos mesmos problemas de infraestrutura e gestão dos serviços de abastecimento de água e esgotamento sanitário de grande parte das capitais brasileiras. O crescimento populacional dificulta a realização de um serviço que historicamente é deficiente. O planejamento urbano ineficiente, aliado a um crescimento desordenado, contribuem para que as provisões de serviços primordiais como os SAE caminhem lentamente. O sistema de esgotamento sanitário da cidade ainda se restringe a uma pequena parcela da população, ou seja, pouco cresceu desde sua implantação entre 1888 e 1920, que mal chega a $10 \%$. A busca por mais espaço e moradia levou a população a residir em áreas de precária urbanização, expandindo em forma horizontal, espalhando a cidade para o meio da floresta e gerando dificuldade de acessar os serviços fornecidos pelo Estado. Este espalhamento, além de promover moradias com aspecto insalubre com risco à saúde, permite que a ocupação se dê em beiras de igarapés, em áreas de inundação, em áreas de cotas baixas e também em áreas de risco de deslizamento, dificultando a instalação de sistemas de tubulação para o abastecimento de água e para a drenagem do esgoto. 
Ainda hoje há relatos de problemas como desabastecimento de água ou falta de serviços de esgotamento sanitário, sendo que esse último não tem previsão para ser resolvido, mesmo com tantas prorrogações da concessão destes serviços em Manaus. A equidade do acesso aos dois está distante. A infraestrutura operacional empregada pela prestadora Manaus Ambiental consegue ser eficiente em relação ao abastecimento de água, mas em relação ao esgotamento sanitário o serviço é ineficiente.

É imperativo ampliar esforços na busca de condições de saneamento que promovam a qualidade de vida, saúde e que respeitem a dignidade da pessoa humana. Ampliar o acesso também diz respeito a levar condições dignas a pessoas que moram em áreas irregulares nas cidades brasileiras. Considera-se que o maior desafio da cidade seja a ampliação do acesso ao sistema de esgotamento sanitário principalmente no que tange às obras de infraestrutura urbana e um arranjo administrativo mais dinâmico que possa integrar os entes públicos, municipal, estadual e o ente privado de forma a reduzir a carência deste serviço.

Há necessidade aqui de ressaltar um aspecto cultural. A população pode não querer se ligar às redes de esgotamento sanitário, em decorrência dos aumentos das tarifas e taxas recorrendo aos "gatos" e isso leva a perdas na distribuição e na qualidade da água. Neste aspecto, o município deve prever formas de fazer com que haja adesão aos novos sistemas implantados, sob o risco de existir a rede e não haver a ligação das residências à mesma. Um novo plano diretor de esgoto foi apresentado no ano de 2016, porém ainda não foi aprovado por todos órgãos competentes. Uma análise deste documento permitirá avaliar as diretrizes que serão tomadas pelos envolvidos para a meta da universalização do serviço.

\section{REFERÊNCIAS}

ARAGÃO, J.; BORGES, J. O acesso ao abastecimento de água e esgotamento sanitário: um estudo de caso na Região Metropolitana de Manaus. In: SICASA e ANPPAS Amazônia. Manaus, 2016. Anais... Manaus: UFAM/ANPPAS, 2016. n.p. Disponível em: <https://www.even3.com.br/anais/ivsicasa/33463-oacesso-ao-abastecimento-de-agua-e-esgotamento-sanitario--um-estudo-de-casona-regiao-metropolitana-de-manaus>. Acesso em: 9 nov. 2016.

ARSAM - Agência Reguladora dos Serviços Públicos Concedidos do Estado do Amazonas. Relatório de atividade 2015. Manaus, 2015. 112 p. Disponível em: <http://www.arsam.am.gov.br/wp/wp-content/uploads/Relat\%C3\%B3riode-atividades-ARSAM-2015.pdf>. Acesso em: 2 dez. 2016. 
BARLOW, M. Água - futuro azul. Como proteger a água potável para o futuro das pessoas e do planeta para sempre. São Paulo: M. Books do Brasil, 2015. p. 312. BRASIL. Leis. Lei Federal no 11.445 de 05 de janeiro de 2007. Estabelece as diretrizes nacionais para o saneamento básico. Disponível em: <http://www. planalto.gov.br/ccivil_03/_ato2007-2010/2007/lei/111445.htm>. Acesso em: 10 nov. 2018.

Ministério da Saúde. Fundação Nacional de Saúde. Manual de Saneamento. 4. ed. Brasília, 2015. 642p. Il. Disponível em: <http://www. funasa.gov.br/site/funasa-publica-a-4a-edicao-do-manual-de-saneamento/ $>$. Acesso em: 11 mar. 2016.

BRITTTO, A. Política pública de saneamento básico: as bases do saneamento como direito de cidadania e dos debates sobre novos modelos de gestão. 2006 Observatório das Metrópoles. Disponível em: <http://observatoriodasmetropoles.net/index. php?option $=$ com_k $2 \& v i e w=i t e m \& i d=1707$ :saneamento- $\mathrm{b} \% \mathrm{C} 3 \% \mathrm{~A} 1$ sico-comodireito-de-cidadania\&Itemid=180>. Acesso em: 25 fev. 2007.

CAMPANHA DA FRATERNIDADE 2016. Disponível em: < http:// campanhas.cnbb.org.br/cf2016>. Acesso em: 05 mar. 2016.

CASTRO, E. Grupo Suez em Manaus, privatização dos serviços de água e impactos sobre as mulheres. Papers do Naea, Belém, n. 217. 2008. Disponível em: < http:// www.naea.ufpa.br/naea/novosite/paper/358>. Acesso em: 08 jun. 2015.

CNI - Confederação Nacional da Indústria. Burocracia e entraves ao setor de saneamento. 2016. Disponível em: < http:/ / arquivos.portaldaindustria.com.br/ app/conteudo_18/2016/01/11/10388/1101-BurocraciaeEntravessaneamento. pdf $>$. Acesso em: 20 abr. 2016.

FIORILLO, C. Curso de direito ambiental brasileiro. 14. ed. São Paulo: Saraiva, 2013. 961p.

GALVÃO JUNIOR, A. C. Desafios para a universalização dos serviços de água e esgoto no Brasil. Revista Panam Salud Publica. 2009, 25(6):548-56.

GIATTI, L. Reflexões sobre Águas de abastecimento e saúde pública: Um estudo de caso na Amazônia Brasileira. Saúde e Sociedade, v. 16, n. 1, p. 134 144, jan./abr. 2007.

Precariedades em saneamento básico, doenças de veiculação hídrica e demais moléstias associadas. In: GIAT'TI, L. (Org.). Fundamentos de Saúde ambiental. Manaus: Editora da Universidade Federal do Amazonas, 2009. p. 24-58. 
GIL, A. Como elaborar projetos de pesquisa. 5. ed. São Paulo: Atlas, 2008.

HELLER, L. Política pública e gestão dos serviços de abastecimento de água e esgotamento sanitário e suas interfaces, a perspectiva da saúde pública. In: HELlER, L; CASTRO, J. (Orgs.). Política pública e gestão de serviços de saneamento. ed. ampl. Belo Horizonte: Editora UFMG; Rio de Janeiro: Editora Fiocruz, 2013. 567p.

O direito humano ao saneamento básico e os novos desafios Artigo de opinião. ASSEMAE postado em 17 de novembro de 2016. Disponível em: <http://www.assemae.org.br/artigos/item/1840odireitohumanoaosaneam en tobasicoeosnovosdesafios? $\mathrm{tmpl}=$ component\&print $=1>$. Acesso em: 25 jan. 2017

HELlER, L; CASTRO, J. (Org.). Política pública e gestão de serviços de saneamento. ed. ampl. Belo Horizonte: Editora UFMG; Rio de Janeiro: Editora Fiocruz, 2013. 567p.

IBGE - Instituto Brasileiro de Geografia e Estatística. Evolução Populacional e Pirâmide Etária 2010. Disponível em: < http://cidades.ibge.gov.br/painel/ populacao.php?lang=\&codmun=130260\&search=amazonas $\mid$ manaus $\mid$ infogr $\%$ E1 ficos:-evolu\%E7\%E3o-populacional-e-pir\%E2mide-et $\%$ E1ria $>$. Acesso em: 14 ago. 2015.

Evolução populacional e pirâmide etária 2016. Disponível em: $<$ http:/ / cidades.ibge.gov.br/xtras/perfil.php?codmun=130260>. Acesso em: 25 nov. 2016.

INSTITUTO TRATA BRASIL. Ranking do Saneamento 2016. Disponível em: <http://portaldoamazonas.com/wp-content/uploads/2016/04/relatoriocompleto.pdf $>$. Acesso em: 08 ago. 2016.

LOPES, A. A oportunidade da parceria para universalizar o saneamento. 2016. ABCONSINDCON. Disponível em: <http://abconsindcon.com.br/opiniao/ aoportunidadedaparceriaparauniversalizarosaneamento/> . Acesso em: 25 fev. 2017.

MADEIRA, R. O setor de saneamento básico no Brasil e as implicações do marco regulatório para a universalização do acesso. Revista do BNDES, Rio de Janeiro, n. 33, p. 123-154, 2010.

MANAUS. PMSB - Plano Municipal de Saneamento Básico de Manaus. Prefeitura Municipal de Manaus. 2014. Disponível em: < http://www2.manaus. am.gov.br/docs/portal/secretarias/casacivil/ugpm_agua/plano_mun_ saneamento_1/24032014_Produto_11.pdf>.Acesso em: 10 set. 2014. 
MARMELSTEIN, G. Curso de direitos fundamentais. 5. ed. São Paulo: Atlas, 2014. xxiv, 536 p.

MINAYO, M. C. de S. O Desafio do Conhecimento: Pesquisa Qualitativa em Saúde. $9^{\circ}$ ed.Revista aprimorada-São Paulo, Hucitec,2006

OLIVEIRA, C. Água e saneamento básico em Manaus, Amazonas - Brasil: valoração econômica em serviços de utilidade pública. Revista Geografia em Questão, v. 4, n. 2, p. 181-196, 2011.

PINHO, R. Teoria geral da constituição e direitos fundamentais. 4. ed. rev. São Paulo: Saraiva, 2003. XVIII, 200p. (Sinopses Jurídicas, v. 17)

PORTAL BRASIL. PAC atendeu 'uma Inglaterra' com saneamento básico em oito anos. 2016. Disponível em: <http://www.brasil.gov.br/ infraestrutura/2016/02/brasil-atendeu-2018uma-inglaterra2019-comsaneamento-basico-entre-2007-e-2015>. Acesso em 26 nov. 2016.

RICHARDSON, R. Pesquisa social: métodos e técnicas. Colaboradores José Augusto de Souza Peres et. al. 3. ed. 16. reimpr. São Paulo: Atlas, 2015. p. 334

SCARAMUSSA, S.; HENKES, J. A utilização do sistema condominial de esgotamento sanitário como política pública para universalização do atendimento com redes de esgotos: o exemplo clássico do Distrito Federal. Revista Gestão \& Sustentabilidade Ambiental, v. 3, n. 1, 2014, p. 310-339.

SEVERINO, A. Metodologia do trabalho científico. 23. ed. rev. e atual. São Paulo: Cortez, 2007. p. 304.

SOUZA, R. R. de. Políticas e práticas de saúde e equidade. Revista da Escola de Enfermagem da USP, v. 41, n. especial, p. 765-770, 2007.

THE WORLD RESOURCES INSTITUTE. World resource 1992-1993. Nova york- oxford university press; 1992. 385p. Disponível em: <http://www.wri. org/sites/default/files/pdf/worldresources1992-93_bw.pdf $>$. Acesso em: 8 jan. 2017.

UN - UNITED NATIONS. General Assembly, Human Rights Council Texts Declaring Water, Sanitation Human Right 'Breakthrough'. 25 de outubro de 2010. Disponível em: <https://www.un.org/press/en/2010/gashc3987.doc. htm>. Acesso em: 8 fev. 2017.

General Assembly Resolution 64/292. The human right to water and sanitation, 2010. Disponível em: < http://www. un.org/en/ga/search/view_doc. asp?symbol=A/RES/64/292>. Acesso em: 25 jun. 2016. 
UN - UNITED NATIONS. Transforming our world: The 2030 agenda for sustainable development. 2015 Disponível em: < https:/ / sustainabledevelopment. un.org/content/documents/21252030\%20Agenda $\% 20$ for $\% 20$ Sustainable $\% 20$ Development\%20web.pdf>. Acesso em: 20 fev. 2016.

WHO/UNICEF. Joint Monitoring Programme. Progress on sanitation and drinking water - 2015 update and MDG assessment, 2015. Disponível em: <http://www.wssinfo.org/fileadmin/user_upload/resources/JMP-Updatereport-2015_English.pdf>. Acesso em: 25 jun. 2016.

WRIGHT, A. Toward a strategic sanitation approach: improving the sustainability of urban sanitation in developing countries. Water and sanitation program. Washington, D.C.: World Bank Group, 1997. Disponível em: < http:// www.bvsde.paho.org/bvsaas/fulltext/toward.pdf>. Acesso em: 28 set. 2016.

YIN, R. Estudo de caso: planejamento e métodos. Tradução: Cristhian Matheus Herrera. 5. ed. Porto Alegre: Bookman, 2015. p. 290 
